\title{
Individual differences in television comprehension
}

\author{
KATHY PEZDEK, SARA SIMON, JANET STOECKERT, and JIM KIELY \\ The Claremont Graduate School, Claremont, California
}

\begin{abstract}
Two experiments explored individual differences in memory and comprehension for adults presented information on television. Experiment 1 tested the correlation between comprehension of television and reading with young adults. The ability to comprehend these two forms of media was significantly correlated $(r=.69)$. This finding is contrary to results from our previous study with third and sixth graders (Pezdek, Lehrer, \& Simon, 1984). Experiment 2 probed two specific individual differences factors as predictors of television comprehension. The results were that good television comprehenders (1) had higher visual/spatial ability, as assessed by psychometric test performance, and (2) were more likely to utilize an imagery-based strategy in the sentence-picture verification task of Clark and Chase (1972) (e.g., "STAR IS ABOVE PLUS"). These results suggest differences in the comprehension processes that operate on information presented in different forms of media.
\end{abstract}

Television is a major source of information for much of the population. Although Americans primarily watch television for entertainment, television is also rated as the primary news source in this country (Roper Organization, 1979). However, the ability of people to comprehend and remember information presented on television is not impressive (see Gunter, Berry, \& Clifford, 1981; Neuman, 1976), and this ability varies widely among individuals (see Berry, Gunter, \& Clifford, 1981, for a review of relevant studies). The current study explores cognitive individual differences in the ability to comprehend information presented on television.

In approaching this issue, one might suppose that comprehension is a general cognitive construct that operates similarly across various types of information. According to this view, comprehension of information presented on television should be cognitively similar to comprehension of information in text. If so, then factors that predict reading comprehension (see Frederiksen, 1982; Hunt, 1978; Hunt, Lunneborg, \& Lewis, 1975; Stevenson, Parker, Wilkinson, Hegion, \& Fish, 1976) should also predict television comprehension. However, we (Pezdek, Lehrer, \& Simon, 1984) found that with third and sixth graders, comprehension of information presented on television and that presented in text were not significantly correlated. This finding held across a range of memory and comprehension measures, for narrative as well as expository materials, and for both age groups. This finding was replicated in a subsequent study with a different group of sixth

We appreciate the assistance we received from Jim Martin and Mike Slovik at Claremont High School and thank their students for participating in this study. We also thank Dale Berger for his statistical advice, Earl Hunt for his helpful comments on this manuscript, and Jane Gray for her editing assistance. Correspondence should be sent to the first author at the Department of Psychology, The Claremont Graduate School, Claremont, CA 91711. graders (Pezdek, Simon, MacKenzie, \& MacBride, 1985). These results suggest that at least some of the processes involved in comprehending television differ from those involved in comprehending text.

Thus, we take as our operating hypothesis the view that television comprehension involves some component cognitive skills and abilities that overlap those involved in text comprehension and some that do not overlap. The purpose of Experiment 1 was to assess the extent of overlap between adults' ability to comprehend television and their ability to comprehend text using a correlational procedure; that is, does the absence of a correlation between comprehension of television and text reported by Pezdek et al. (1984) apply to adults? The purpose of Experiment 2 was to explore cognitive abilities hypothesized to be in the nonoverlapping area, that is, those that uniquely predict television comprehension. Specifically, Experiment 2 tested two factors hypothesized to predict individual differences in television comprehension: facility manipulating visual/spatial material and the ability to integrate visual and verbal information.

The selection of these two factors follows from Anderson and Lorch's (1983) process model for television comprehension and from our research with children (Pezdek \& Hartman, 1983; Pezdek \& Stevens, 1984). According to Anderson and Lorch's model, the process of comprehending television involves an interplay between listening to the audio channel, watching the visual channel, and integrating these two messages. Important to this analysis is the semantic integration of visual information with the simultaneously presented auditory/verbal material. Consistent with this model, young children find the visual information on television more salient and memorable than the audio material (Pezdek \& Stevens, 1984), and children use the visually presented information to guide their comprehension of auditorily presented material (Pezdek \& Hartman, 1983). 
These findings suggest that the facility to interpret nonverbal visual materials and the ability to effectively integrate visual and verbal materials may underlie individual differences in television comprehension. These attributes were examined in Experiment 2 by testing (1) visual/ spatial ability as measured by a psychometric paperfolding test and (2) the strategy used by subjects to perform the sentence-picture verification task of Clark and Chase (1972) (e.g., "STAR IS ABOVE PLUS"). The rationale for the selection of these tasks is developed further in the introduction to Experiment 2.

\section{EXPERIMENT 1}

\section{Method}

Subjects. The subjects were 97 juniors and seniors who participated as part of a class exercise at Claremont High School. Students in five social studies classes participated as a group. The students were from an upper-middle-class suburban area, and all spoke English as their primary language. There were approximately equal numbers of male and female students.

Materials and Procedure. Each subject was assessed on three tasks: (1) a test of television comprehension and (2) a test of text comprehension that were developed for this study and (3) a standardized test of reading ability. The latter test was included to validate the text comprehension test developed for this study. The standardized reading test was the Reading/Vocabulary Subtest of the Test of Adolescent Language (TOAL). Performance on this subtest significantly correlates (Pearson $r=.82$ ) with performance on the reading total from the Comprehensive Test of Basic Skills (CTBS) with junior high-school students. This test took about $12 \mathrm{~min}$ to administer.

The television and text materials used in this study were developed from segments of news presented on network television. Twelve segments of news were selected. Each segment was approximately 2 min long and satisfied the following criteria: (1) that four comprehension questions could be generated from each; (2) that comprehension of the segment did not require prerequisite knowledge, and answers to the selected comprehension questions could not easily be inferred from general knowledge; and (3) that the visual portion of the segment primarily included relevant filmed material that was a dynamic part of the information presented, rather than simply "talking heads" format. Some of the topics were a murder trial in Georgia, a Greenpeace demonstration on top of Big Ben, a regional political feud in Israel, the capture of two escaped convicts from a North Carolina jail, and Libya's announcement of a desert irrigation plan. The news segments were also recorded 6 months prior to conducting the experiment to ensure that they were not familiar to subjects.

The 12 segments were randomly assigned to two sets of $6 \mathrm{seg}$ ments each, with the restriction that the duration of each set be approximately the same (total times for the two sets were $11.8 \mathrm{~min}$ and $11.7 \mathrm{~min}$ ). Within each set, the 6 segments were randomly arranged and recorded in one order. In the television version, the 6 segments in each set were edited together on videotape with a leader introducing the series as the daily news. The leader was also recorded from network news to suggest that the series was authentic. The television version was in color and presented on a 19-in. Sony Trinitron.

In the text version, the six segments in each set were typed transcripts of the audio track from each television segment, presented in the same order utilized in the television version of each set. Although in the television version of each segment the visual information was relevant to the simultaneously presented auditory/verbal information, the verbal information was comprehensible when presented alone in the text condition. To enhance the realism of the reading material, the subjects were told that they would be reading typed transcripts of articles from magazines. For the text condition, it was necessary to make some minor changes in the transcripts of the television segments to make them more authentic and readable. This included eliminating phrases such as "as we can see here...." Segments were typed one to a page. The subjects read one segment at a time and were paced through the sequence at a rate of 2 min per segment. One or 2 subjects in each class did not finish each story at this rate. The data from these subjects were not included in the study. Pacing of the reading was deemed necessary, however, to control for exposure duration in the television and text conditions and to prevent the subjects from reading through each segment more than once.

Four comprehension questions were generated from the information presented on the audio track of each segment for use in both the television and the text conditions. Four questions were constructed for each of six segments for a total of 24 comprehension questions. The 4 questions for each segment were presented sequentially, and the segments were tested in the order of presentation. Each question probed information central to the theme of the segment. The following are the 4 comprehension questions from the segment on the murder trial: (1) Describe the location in Georgia where the alleged murder took place. (2) What does the prosecution claim to be the suspect's motivation for allegedly murdering the man? (3) What is the suspect's alibi? (4) Who is the most convincing witness against the suspect? Questions were read by the experimenter, with each repeated once, and the subjects wrote their answers in booklets provided. Each answer was scored as being correct or incorrect. The acceptable "correct" answers were specified in advance, making the scoring of answers quite clear-cut. The scores for the television and the text conditions ranged from 0 to 24 .

The subjects were presented the television version of one set of segments and the text version of the other set of segments, with the assignment of set to media condition and to order of presenting the two media conditions varied across classes. In both conditions, the subjects were instructed to pay close attention to each segment because they would be tested afterward. The experiment was conducted on 2 consecutive days for each class. For three classes of subjects, on the first day, the television version of one set of segments was presented first, followed in $3 \mathrm{~min}$ by the test on this set (the 3 min were filled by the experimenters' distributing materials and reviewing directions). After the test, these classes completed the TOAL standardized reading test. On the second day, these classes read the text version of the other set of segments, followed in $3 \mathrm{~min}$ by the test on this set. The other two classes of subjects participated in the same sequence, with the exception that the order of presenting the television and the text conditions was interchanged.

\section{Results}

Comprehension scores in both conditions ranged from 0 to 24 correct per subject. The mean comprehension score in the television condition was $10.80(S D=4.00)$ and in the text condition $12.22(S D=4.70)$. The principal purpose of Experiment 1 was to test the correlation between comprehension of television and text with adults. Contrary to the results reported with third and sixth graders in our previous study (Pezdek et al., 1984), Experiment 1 yielded a significant positive correlation between comprehension of television and text (Pearson $r=.69, p<.001)$.

To test the validity of the reading test developed for this study, the TOAL standardized reading test also was administered to each subject. Performance on the TOAL was within the normal range for this test (mean scaled 
score $=9.46, S D=3.16$ ). The correlation between performance on the text comprehension test developed for this study and TOAL performance was significant (Pearson $r=.62, p<.001$ ). The text comprehension test developed for this study is thus a valid test for assessing reading ability.

There are several explanations for why the adults showed a positive correlation between television comprehension and text comprehension, whereas third and sixth graders did not (Pezdek et al., 1984). One explanation is that the difference is due to differences in the materials used. Adults in Experiment 1 saw standard news segments, whereas the children tested by Pezdek et al. saw television and text versions of both narrative materials (animated folk tales) and expository materials (lesson-like segments from the Children's Television Workshop program " $3 \cdot 2 \cdot 1$ CONTACT"). The absence of a relation between television and text comprehension was consistent with both types of materials. Thus, although the difference in materials cannot be dismissed, the structural similarity of the expository materials used by Pezdek et al. and the news segments used in the current study reduce the plausibility of this interpretation.

Another interpretation of the difference between the results of the current study and those of Pezdek et al. (1984) is that perhaps the comprehension scores were less reliable for the younger age groups than for adults. Although this interpretation is plausible, additional data reported by Pezdek et al. argue against this view. Children in the previous study also were administered a standardized reading test with documented reliability. The pattern of results was corroborated with this independent measure. The correlation between text comprehension and the standardized reading test was significant for third (Pearson $r=.40$ ) and sixth graders (Pearson $r=.53$ ); however, performance on the standardized reading test was not significantly correlated with television comprehension for either third (Pearson $r=.24$ ) or sixth graders (Pearson $r=.14)$. Because the items on the text comprehension test and the television comprehension test were identical, it is difficult to argue that the absence of a significant correlation between television comprehension and standardized reading test performance, in light of the significant correlation between text comprehension and standardized reading test performance, is due simply to insufficient reliability of the comprehension test.

A more convincing explanation for the difference in results between children in the previous study and adults in the present study is based on a model of reading proposed by LaBerge and Samuels (1974). This model assumes that reading involves a hierarchy of processes from lower order perceptual and decoding processes to higher order comprehension processes. Whereas the perceptual and decoding aspects of reading provide a bottleneck in the reading process for younger children (Curtis, 1980), more mature readers (Samuels, LaBerge, \& Bremer, 1978) and better readers (Patberg, Dewitz, \& Samuels,
1981) perform these lower order processes more automatically, and thus have more attention to allocate to comprehension processes. Because the perceptual and decoding processes of reading are relatively less automatic for beginning readers, and because these decoding processes are not components of television comprehension, young children who have difficulty reading do not necessarily have difficulty comprehending information presented on television. On the other hand, since these lower order processes in reading are relatively automatic for adults, the set of component processes that differentiate good from poor reading is likely to provide more overlap with the set of component processes that differentiate good from poor television comprehension for adults than for less mature readers. This has been the explanation for a similar finding, that the correlation between listening comprehension and reading comprehension increases with age after third grade (Curtis, 1980).

The significant correlation between television comprehension and reading comprehension in Experiment 1 suggests that $48 \%$ of the variance in television comprehension can be explained by factors related to reading ability. In other words, this $48 \%$ represents the overlap between the component cognitive skills and abilities involved in television comprehension and those involved in text comprehension. The purpose of Experiment 2 was to explore the skills and abilities hypothesized to be in the nonoverlapping area, that is, the skills and abilities that specifically predict television comprehension.

\section{EXPERIMENT 2}

Two factors were hypothesized to affect television comprehension: the ability to manipulate visual/spatial information and the ability to integrate visual and verbal material. These abilities were deemed necessary for television comprehension for numerous reasons. Regarding the importance of visual/spatial manipulation ability to television comprehension, several television researchers (see Greenfield, 1987; Salomon, 1983) have speculated that "television literacy" is distinguished from "reading literacy" by the visual cues that are unique to the television medium. Furthermore, Salomon and Cohen (1977) identified certain skills that are prerequisite to comprehending visual features of television, such as cuts, spatial fragmentations, zooms, and so forth, and found that mastery of these skills was not correlated with readingrelated skills in children. Because television utilizes subtle visual cues to communicate change in time, place, perspective shift, and so forth, it seems reasonable to predict that subjects with high visual/spatial ability would interpret these visual cues more effectively and consequently be able to comprehend information presented in this medium better than would subjects with low visual/spatial ability. The visual/spatial test utilized in this experiment was the paper-folding test produced by the Educational Testing Service. This is a multiple-choice test that requires 
subjects to visualize how a two-dimensional figure would look in three dimensions if folded along specified lines.

The second factor, the ability to integrate visual and verbal information, was investigated by a task developed by Clark and Chase (1972). In this paradigm subjects see a sentence, such as "STAR IS ABOVE PLUS," followed by a picture, either " *" or " + ." The task of the subject is to decide, as rapidly as possible, whether the picture is a true depiction of the sentence. Four types of trials are arrived at by combining affirmative or negative sentences with pictures that are true or false depictions of the sentence: true affirmative (TA), false affirmative (FA), false negative (FN), and true negative (TN). Two response-time measures are recorded. Comprehension response time (RT) is the time from the onset of the sentence until the subject depresses a key that terminates the display of the sentence and then presents the picture. Verification RT is the time from the onset of the picture until the subject presses the true or false key.

A model was developed by Carpenter and Just (1975), who hypothesized that the sentence-picture verification task involves three stages: internally representing the sentence, internally representing the picture, and comparing these two internal representations. According to their model, response time to represent the sentence and response time to compare this representation with the picture vary as a function of the type of trial. In particular, response time is predicted to increase with the number of constituent comparisons involved in correctly representing and comparing the sentence with the picture. The model predicts the ordering from the least to the most number of comparisons required, and consequently the response times of TA, FA, FN, and TN. Furthermore, it is predicted that response time will be a linear function of this interval scale. (See Carpenter and Just, 1975, for a more detailed explanation of this model.) Although this model is not without criticism (see Catlin \& Jones, 1976; Tanenhaus, Carroll, \& Bever, 1976), it generally handles the data quite well.

The basis for our use of the sentence-picture verification task of Clark and Chase (1972) to predict television comprehension is derived from the results of MacLeod, Hunt, and Mathews (1978), who noted that the data of most of their subjects were well fit by Carpenter and Just's (1975) "constituent comparison model." However, the data for about $25 \%$ of their subjects deviated from the predictions. These deviations can be explained in terms of an imagery-based strategy (also see Clark \& Chase, 1972; Tversky, 1975). According to this imagery-based strategy, the sentence is internally represented pictorially rather than propositionally, and the sentence-picture comparison involves a comparison of the image generated from the sentence with the presented picture. Comprehension RT is thus longer when the imagery strategy is used rather than the verbal strategy, because it takes longer to generate an image than a propositional representation of a sentence, and verification RT is not a linear function of the type of trial, as found with the verbal strategy. Two groups of subjects can thus be isolated on the basis of the strategy used in Clark and Chase's (1972) sentencepicture verification task. Subjects who utilize a verbally based propositional strategy (1) show a linear trend in verification $R T$ as a function of the type of relationship between the sentence and the picture, (2) have longer verification RTs, and (3) have shorter comprehension RTs than do subjects using an imagery strategy. Subjects utilizing an imagery-based strategy (1) show a nonlinear trend in verification $R T$ as a function of the type of relationship between the sentence and the picture, (2) have shorter verification RTs, and (3) have longer comprehension RTs than do subjects using the verbally based propositional strategy.

Experiment 2 tests whether individual differences in the strategy used to perform Clark and Chase's (1972) sentence-picture verification task predict comprehension of television. This prediction follows from the notion that semantic processing and integration of visual and verbal information, as required in the Clark and Chase (1972) task, appear to be important aspects of television comprehension. Much of television comprehension relies on semantically integrating information presented visually (e.g., Sue Ellen runs a stop sign and nearly hits a pedestrian) with information presented verbally (e.g., J. R. exclaims, "Sue Ellen, your drinking is going to be the end of us!"). Furthermore, MacLeod et al. (1978) found that the two groups of subjects in their study did not differ in psychometric measures of verbal ability. This task is thus not simply a test of reading ability.

\section{Method}

Subjects. Thirty-eight subjects from Experiment 1 participated individually in Experiment 2. These included 19 subjects selected from the top of the distribution of television comprehension scores (the high television group), and 19 subjects from the bottom of the distribution (the low television group). Subjects were pragmatically selected utilizing the following rule. Each subject from Experiment 1 was telephoned and asked if he/she would come to the university campus to participate in a follow-up study for about an hour. A $\$ 15$ stipend was offered. All subjects who could be contacted, volunteered to participate, could be scheduled, and showed up were participants in Experiment 2. To equate the number of subjects selected from the top and bottom of the distribution of television comprehension scores, follow-up telephone calls were made to reschedule a few subjects who did not show up for their first scheduled appointment. Sex and age of subjects were not specifically controlled for. The mean television comprehension score in the high television group $(M=16.16, S D=1.57$, range $=14-21)$ was significantly greater than the mean score in the low television group $(M=$ $7.63, S D=1.74$, range $=3-9$ ).

Procedure. Subjects participated individually at the Claremont Graduate School campus in one session that lasted about $1 \mathrm{~h}$. Each subject first completed the paper-folding test of spatial ability produced by the Educational Testing Service. This test, similar to the spatial ability component of the Washington Pre-College test used by MacLeod et al. (1978), is a multiple-choice test that requires subjects to visualize how a two-dimensional figure would look in three dimensions if folded along specified lines. Subjects were given $5 \mathrm{~min}$ to complete as many of the 16 problems as possible. After a brief rest, subjects participated in the sentence-picture verification task. 
The Clark and Chase (1972) sentence-picture verification task was administered exactly as conducted by MacLeod et al. (1978). Subjects were seated in front of an Apple I+ microcomputer with their left and right index fingers on two specified keys. They read the following instructions, adopted from MacLeod et al. (1978), on the computer display:

You will be presented a number of trials in which a sentence is presented followed by a picture. Your task is to decide whether the picture is true or false in relation to the sentence. On each trial, you will first see a sentence, such as "STAR IS ABOVE PLUS." This sentence will be displayed for as long as you need. When you are ready for the picture, press either key. A half-sec later, a picture will appear. This picture will either be " + " or " + ." Your task is to indicate whether this picture is true or false with relation to the sentence you just read. If it is true, press the key labeled TRUE with your right index finger. If it is false, press the key labeled FAISE with your left index finger. The sentence for the next trial will be presented shortly thereafter. We are interested in how long you spend reading the sentence and how long you take to make your TRUE-FALSE decision. You should try to go as quickly as you can without making errors.

Sixteen sentence-picture pairs were created by combining three binary dimensions of the sentence, (STAR, PLUS), (IS, IS NOT), (ABOVE, BELOW) with each of the two pictures $(++,++)$. The experiment was conducted on an Apple II+ microcomputer with a Mountain Hardware Clock utilized to control and record the time.

After the instructions, the subjects were given a block of 16 practice trials. Within each block, each of the 16 types of sentence-picture pairs was presented once in a random order. The subjects were given the opportunity to ask questions about the procedure after the practice session.

After practice, the subjects were given two blocks of 64 experimental trials. Each block included four repetitions of each of the 16 types of sentence-picture pairs randomly ordered. There was a brief rest period between the two blocks of trials. On each trial a fixation point appeared for $500 \mathrm{msec}$, followed by the stimulus sentence. The sentence was presented horizontally at the center of the screen. After reading the sentence, the subject pressed either the TRUE or the FALSE key. The picture replaced the sentence on the screen after 500 msec. On each trial, comprehension RT was measured from the onset of the sentence to the initial keypress. Verification RT was measured from the onset of the picture until the subject pressed the TRUE or FALSE key. Immediately after each trial, a feedback message was displayed for $500 \mathrm{msec}$ if the correct response had been indicated; the word CORRECT was displayed with the verification RT for that trial. Subjects were instructed that if there was no message displayed during this period, they had made an incorrect response. The time between the offset of the feedback and the onset of the fixation point for the next trial was $500 \mathrm{msec}$.

\section{Results}

Visual/spatial ability task. The paper-folding test of visual/spatial ability was included in Experiment 2 to test whether subjects with high visual/spatial ability were better television comprehenders than subjects with low visual/ spatial ability. This hypothesis was confirmed. Subjects in the high television group scored significantly higher on the visual/spatial test $(M=12.26, S D=4.23)$ than did subjects in the low television group $[M=8.11, S D=$ $2.66 ; t(36)=3.63, p<.001]$. Scores on the visual/ spatial ability test ranged from 0 to 16 items correct. In addition, the correlation between performance on the television comprehension test and the visual/spatial ability test was significant (Pearson $r=.54, p<.001$ ). Individual differences in visual/spatial ability are thus predictive of television comprehension.

Sentence-picture verification task. The mean verification RT for each of the four types of test trials and the mean comprehension RT were computed for each subject. Data were analyzed only for trials on which the response was correct and for which the verification RT was within $3 S D$ s of the mean RT of all subjects for that trial type. Based on these criteria, 5.6\% of the trials were eliminated.

Because the focus of this experiment was on the individual differences between the high and low television groups, the results center on analyses involving group differences. Our first task was to establish a criterion for deciding which subjects utilized the verbally based constitutent comparison strategy for comparing the picture with the sentence, and which subjects utilized some other strategy. A different criterion than that utilized by MacLeod et al. (1978) was adopted in the present study for determining the fit of subjects' data to the constituent comparison model. Each subject's mean verification RTs for TA, FA, FN, and TN trials, in this order, were analyzed using a trends test. For each subject, the sum of squares accounted for by the linear component was recorded. This was utilized as an index of the relative frequency with which each subject employed the constituent comparison strategy. The 38 subjects were then split at the median value of the linear sum of squares into a high linear group and a low linear group. The percent of variance accounted for by the linear trend in sentence-picture verification $R T$ was then computed for each subject. The mean percent of variance for the high linear group $(M=$ $75.8 \%, S D=24.2)$ and the low linear group $(M=$ $36.2 \%, S D=27.3$ ) differed by 15.7 standard deviation units.

Subjects in the high linear group were those who utilized the verbally based constituent comparison model more often than subjects in the low linear group. Subjects whose data were better fit by quadratic, cubic, or other trends were included in the low linear group. Accordingly, subjects who utilized the imagery-based strategy described by MacLeod et al. (1978) were more likely to be included in the low linear than in the high linear group. The major advantage of the criterion utilized in this study for determining subjects' fit to the model over that used by MacLeod et al. (1978) is that the data of all subjects are utilized with the present method rather than deleting the "intermediate-fit" group.

The major purpose of this experiment was to test whether differences in the strategy used to verify a sentence and a picture could be used to predict television comprehension ability. In particular, we predicted that subjects in the high television group would be more likely to fit the low linear pattern and that subjects in the low television group would be more likely to fit the high linear pattern. As one test of this prediction, we looked at the number of subjects who fell in each cell of a $2 \times 2$ matrix 
defined by conditions of high versus low television group and high versus low linear pattern of results. These data, presented in Table 1, are quite convincing. High television comprehenders were more likely to fit the low linear pattern than the high linear pattern, and low television comprehenders were more likely to fit the high linear pattern than the low linear pattern $\left[\chi^{2}(1)=5.16, p<.05\right]$. In addition, as predicted, the percent of variance accounted for by the linear trend in sentence-picture verification RT was significantly higher for the low television group ( $M=$ $66.3 \%, S D=31.3$ ) than for the high television group $[M=45.6 \%, S D=30.9 ; t(36)=2.06]$.

To test the above prediction further, the verification RTs for TA, FA, FN, and TN trials were plotted for low television and high television groups separately. These data are presented in Figure 1. A 2 (high vs. low television group) $\times 4$ (type of sentence-picture relationship) analysis of variance was performed on these data. As predicted, verification RT was faster for the high television group (mean RT $=785 \mathrm{msec}$ ) than for the low television group (mean RT $=1,120 \mathrm{msec}$ ) $[F(1,36)=7.63, \mathrm{MSe}$ $=557]$. Also, verification RT was significantly affected by the type of sentence-picture relationship $[F(3,36)=$ $28.03, M S e=31$ ]. However, the interaction of these two variables was not significant $[F(3,108)=1.92]$.

We predicted that if high television subjects were using an imagery-based strategy, then comprehension RT should be longer for subjects in the high television group than for subjects in the low television group. Although this result was in the predicted direction, mean comprehension RT did not significantly differ between the high television group (mean $\mathrm{RT}=2,877 \mathrm{msec}, S D=1,523$ ) and the low television group (mean RT $=2,402 \mathrm{msec}, S D=$ $1,052)$. Nonetheless, these data reflect the predicted pattern of a trade-off between verification RT and comprehension RT for the high and low television groups. Together, the results from the sentence-picture verifica-
Table 1

Number of Subjects in the Low and High Television Groups Who Fit the Low Linear Versus High Linear Pattern of Verification RTs

\begin{tabular}{ccc}
\hline Group & $\begin{array}{c}\text { Low Linear } \\
\text { Pattern }\end{array}$ & $\begin{array}{c}\text { High Linear } \\
\text { Pattern }\end{array}$ \\
\hline Low Television & 6 & 13 \\
High Television & 13 & 6 \\
\hline
\end{tabular}

tion task generally support the hypothesis that subjects who utilize a nonverbal strategy (i.e., low linear subjects) comprehend television better than do subjects who utilize a verbal strategy (i.e., high linear subjects).

Multiple regression analysis. A multiple regression analysis was conducted to assess the role of (1) the percent of variance accounted for by the linear trend in sentence-picture verification RT, and (2) visual/spatial ability in predicting television comprehension, with the variance due to performance on the standardized reading test removed first. The variance due to reading ability was entered first in the multiple regression to examine which factors were significant above and beyond factors related to reading ability. The other two factors were entered in a stepwise fashion.

Television comprehension was significantly related to performance on the standardized reading test (simple $r=.66$, cumulative $R^{2}=.43$ ) and the percent of variance accounted for by the linear trend in verification RT (simple $r=-.34$, cumulative $R^{2}=.50$ ). Performance on the psychometric test of visual/spatial ability was not significant (simple $r=.54$ ), most likely because of the significant correlation between performance on this test and the percent of variance accounted for by the linear trend in verification RT (simple $r=-.42$ ).

On the other hand, the correlation between the standardized reading test and the percent of variance accounted for by the linear trend in verification RT was not significant (simple $r=-.13$ ). However, the correlation

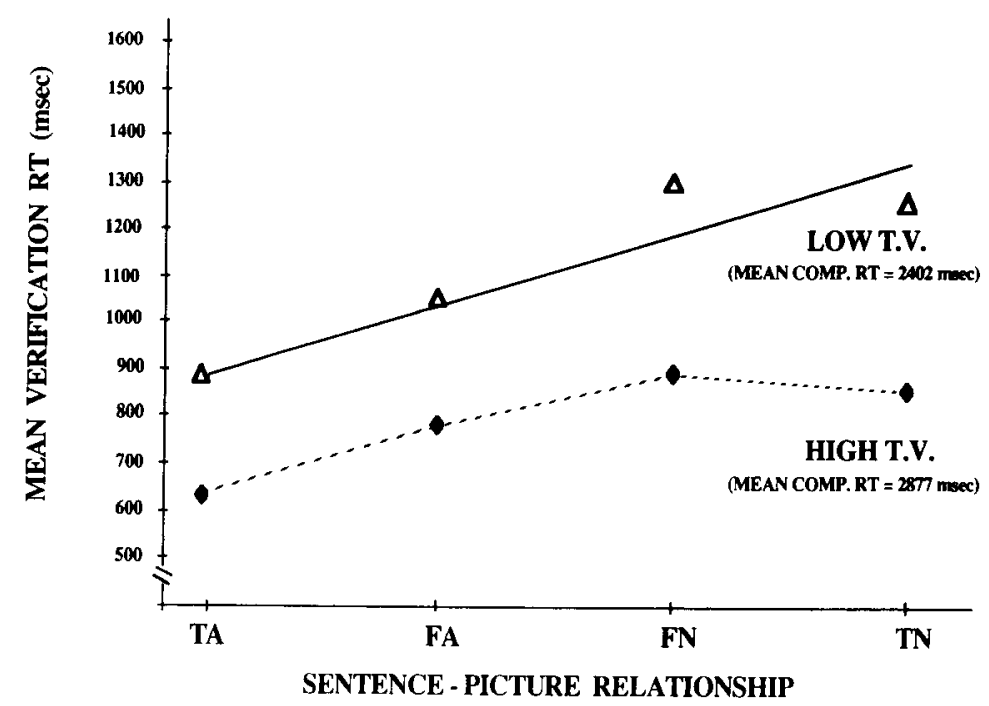

Figure 1. Mean verification RT for the high television group and the low television group as a function of the sentence-picture relationship. 
between the standardized reading test and the visual/spatial test was significant (simple $r=.48$ ), although slightly less than the comparable correlation with television comprehension (simple $r=.54$ ).

The results of the multiple regression analysis are consistent with those reported previously. However, the results of this analysis must be interpreted with caution due to the fact that the television comprehension measure did not include values from the middle of the distribution on this measure. In other words, the 19 subjects in the high television group (range of scores on the television comprehension test $=14-21$ ) and the 19 subjects in the low television group (range $=3-9$ ) did not include any subjects who scored 10 to 13 . Thirty-nine of the 97 subjects in Experiment 1 (i.e., $40 \%$ ) fell within this middle interval. The results of this analysis are thus exaggerated over what might be predicted if the television comprehension measure were a continuous distribution.

\section{GENERAL DISCUSSION}

The large majority of the research on comprehension has, in fact, examined text comprehension, and generalized from these findings with verbal materials to comprehension more generally. The present study is part of a program of research examining differences in comprehension across various forms of media; differences between comprehension of television and test have been of particular interest.

The principal result of Experiment 1 was that comprehension of television and text was positively correlated among adults. This finding differs from the results of Pezdek et al. (1984) with third and sixth graders. One interpretation of this difference is that for more mature readers, for whom many of the decoding processes involved in reading are relatively automatic, the set of component skills that discriminates good from poor reading substantially overlaps the set of component skills that discriminates good from poor television comprehension.

The results of Experiment 1 address the size of the overlapping area of the set of cognitive skills and abilities underlying television comprehension and the set involved in text comprehension. Experiment 2 tested whether individual differences in television comprehension could be predicted by performance on two tasks that involve processes that are not significant components of the reading process.

The two individual differences factors tested in Experiment 2 did significantly predict television comprehension. In short, subjects who were good at comprehending information presented on television (1) had higher visual/ spatial ability, as assessed by psychometric test performance, and (2) were more likely to utilize an imagerybased strategy on the information processing test of sentence-picture verification. Subjects who were poor at comprehending information presented on television (1) had lower visual/spatial ability, and (2) were more likely to utilize a verbally based propositional strategy for sentence-picture verification.

The results suggest that subjects select a strategy for performing the sentence-picture verification task that is appropriate to their individual ability. Specifically, in this study, as well as in the study by MacLeod et al. (1978), subjects with higher visual/spatial ability were more likely to utilize the imagery-based strategy than were subjects with lower visual/spatial ability. Furthermore, subjects with higher visual/spatial ability and those who utilized the imagery-based strategy in sentence-picture verification were also better comprehenders of television. These results suggest that television comprehension significantly draws on the cognitive abilities that are assessed in these two predictor tasks.

What is there about the cognitive process of comprehending television that draws on the ability to utilize an imagery-based strategy in sentence-picture verification and on high visual/spatial ability? Again, we rely on the model for television comprehension offered by Anderson and Lorch (1983), and we conceptualize television comprehension as a process by which the viewer utilizes the visually presented information to guide the comprehension process. Accordingly, subjects who have more facility interpreting nonverbal visual material and those who can accurately integrate visual and verbal material would be more effectively guided in the process of television comprehension.

In addition, at a more molar level, it has been hypothesized that the features of television literacy that distinguish it from reading literacy are those that involve interpreting and manipulating the visual cues that are unique to the medium (see Greenfield, 1987; Salomon, 1983). Examples of such visual cues are such features of television as cuts, pans, zooms, spatial fragmentations, and so forth. These features of television literacy appear to draw on the cognitive abilities that are assessed in the two predictor tasks utilized in the present study.

The finding that television comprehension was predicted by performance on both an information-processing task of sentence-picture verification and a psychometric test of visual/spatial ability is especially convincing considering the nature of the television comprehension test used in the present study. In order to utilize the same test questions in the television and text conditions in the present study, it was necessary to construct questions based on information that was available in both conditions. Thus, all questions were based upon information that had been presented on the auditory/verbal channel on television, although this information was certainly enhanced by visually presented information in the television condition. However, the fact that television comprehension could be predicted by performance on these other tests is especially convincing, given that the television comprehension test in the present study was not a test of comprehension of exclusively visually presented information."

This research has implications for actualizing the educational benefits of television by identifying individuals 
whose cognitive abilities would be predictive of good television comprehension. This research suggests that individuals with high visual/spatial ability and those who utilize the imagery-based strategy for sentence-picture verification would be better suited to instructional materials presented on television than would other individuals.

\section{REFERENCES}

Anderson, D. R., \& Lorch, E. P. (1983). Looking at television: Action or reaction? In J. Bryant \& D. R. Anderson (Eds.), Understanding children's television (pp. 1-33). New York: Academic Press.

Berry, C., Gunter, B., \& Clifford, B. (1981). Memory for televised information: A problem for applied and theoretical psychology. Current Psychological Reviews, 1, 171-192.

Carpenter, P. A., \& Just, M. A. (1975). Sentence comprehension: A psycholinguistic processing model of verification. Psychological Review, 82, 45-73.

CATLIN, J., \& JONES, N. K. (1976). Verifying affirmative and negative sentences. Psychological Review, 83, 497-501.

Clark, H. H., \& ChaSe, W. G. (1972). On the process of comparing sentences against pictures. Cognitive Psychology, 3. 472-517.

CURTIS, M. E. (1980). Development of components of reading skill. Journal of Educational Psychology, 72, 656-669.

FrederiKSEN, J. R. (1982). A componential theory of reading skills and their interactions. In R. J. Sternberg (Ed.), Advances in the psychology of human intelligence (Vol. 1, pp. 125-180). Hillsdale, NJ: Erlbaum.

GREENFIELD, P. M. (1987). Electronic technologies, education, and cognitive development. In D. Berger, K. Pezdek, \& W. P. Banks (Eds.), Applications of cognitive psychology: Problem solving, education and computing (pp. 17-32). Hillsdale, NJ: Erlbaum.

GunTer, B., BerRY, C., \& CuFford, B. R. (1981). Release from proactive interference with television news items: Further evidence. Journal of Experimental Psychology: Human Learning \& Memory, 7, 480-487.

Hunt, E. B. (1978). Mechanics of verbal ability. Psychological Review, $85,109-130$

Hunt, E. B., Lunneborg, C. E., \& Lewis, J. (1975). What does it mean to be high verbal? Cognitive Psychology, 7, 194-227.

LABERGE, D., \& SAMUELS, S. J. (1974). Toward a theory of automatic processing in reading. Cognitive Psychology, 6, 293-323.

MacLeod, C. M., Hunt, E. B., \& Mathews, N. N. (1978). Individual differences in the verification of sentence-picture relationships. Journal of Verbal Learning \& Verbal Behavior, 17, 493-507.

Neuman, W. R. (1976). Patterns of recall among television news viewers. Public Opinion Quarterly, 40, 115-123.

Patberg, J., Dewitz, P., \& Samuels, S. J. (1981). The effect of context on the size of the perceptual unit used in word recognition. Journal of Reading Behavior, 13, 33-48.

Pezdek, K., \& Hartman, E. F. (1983). Children's television viewing: Attention and comprehension of auditory versus visual information. Child Development, 54, 1015-1023.
Pezdek, K., Lehrer, A., \& Simon, S. (1984). The relationship between reading and cognitive processing of television and radio. Child Development, 55, 2072-2082.

Pezdek, K., Simon, S., Mackenzie, L., \& MacBride, L. (1985, April). Individual differences in television and text comprehension. Paper presented at the meeting of the Society for Research in Child Development, Toronto.

Pezdek, K., \& Stevens, E. (1984). Children's memory for auditory and visual information on television. Developmental Psychology, 20, 212-218.

Roper Organization, Inc. (1979). Public perceptions of television and other mass media: A twenty-year review 1959-1978. New York: Television Information Office.

Salomon, G. (1983). Television literacy and television vs. literacy. In R. W. Bailey \& R. M. Fosteim (Eds.), Literacy for life: The demand for reading and writing. New York: The Modern Language Association of America.

Salomon, G., \& Cohen, C. C. (1977). Television formats, mastery of mental skills and the acquisition of knowledge. Journal of Educational Psychology, 69, 612-619.

Samuels, S. J., LaBerge, D., \& Bremer, C. (1978). Units of word recognition: Evidence for developmental changes. Journal of Verbal Learning \& Verbal Behavior, 17, 715-720.

Stevenson, H. W., Parker, T., Wilkinson, A., Hegion, A., \& FISH, E. (1976). Longitudinal study of individual differences in $\operatorname{cog}-$ nitive development and scholastic achievement. Joumal of Educational Psychology, 68, 377-400.

Tanenhaus, M. K., Carroll, J. M., \& Bever, T. G. (1976). Sentence-picture verification models as theories of sentence comprehension: A critique of Carpenter and Just. Psychological Review, 83, 310-317.

TVERSKY, B. (1975). Pictorial encoding of sentences in sentencepicture verification. Quarterly Journal of Experimental Psychology, 27, 405-410.

\section{NOTE}

1. One interpretation of the results of this study, offered by an anonymous reviewer, is that perhaps individuals with high visual/spatial ability and those who used the imagery-based strategy comprehend television better because they were less distracted by irrelevant visual material that is typical of television news. Although this interpretation is plausible, it does not appear to be a major factor with the materials used in the present study. The news segments used in this study were selected such that the visually presented material was generally relevant to the auditorily presented material, providing a good "fit." To test this assumption, 31 additional college students were shown the 12 segments of television news utilized in this study. They rated each on a scale from 1 (very poor fit between the information presented on the visual and auditory channels) to 5 (very good fit). The mean rating per segment was 3.15 (range $=2.03-4.43$ ), indicating that the fit between the auditory and the visual channels in the news segments utilized was reasonably good.

(Manuscript received March 18, 1986; revision accepted for publication November 25, 1986.) 